\title{
Correction to: Ambrisentan \pm tadalafil in WHO functional class II/III pulmonary arterial hypertension: a guide to its use in the EU
}

\author{
Katherine A. Lyseng-Williamson ${ }^{1}$ (I) . Jürgen Behr ${ }^{2}$
}

Published online: 23 November 2018

(c) Springer Nature Switzerland AG 2018

\section{Correction to: Drugs \& Therapy Perspectives https://doi.org/10.1007/s40267-018-0531-1}

Page 294, column 1, first sentence: the following text, which previously read:

"In a secondary analysis of survival outcomes in the modified intent-to-treat population of AMBITION, mortality rates did not differ to a significant extent between the ambrisentan + tadalafil and pooled monotherapy groups at the end of the 24-week trial (10 vs $14 \%$ of patients; HR 0.67 ; 95\% CI 0.42-1.08; $\log$-rank $p=0.10$ ) [24]".

Should read:

"In a secondary analysis of survival outcomes in the modified intent-to-treat population of AMBITION, mortality rates did not differ to a significant extent between the ambrisentan + tadalafil and pooled monotherapy groups at the end of the study (10 vs $14 \%$ of patients; HR $0.67 ; 95 \%$ CI $0.42-1.08 ; \log$-rank $p=0.10$; median time on study drug 96 and 91 weeks, respectively) [24]".

The original article can be found online at https://doi.org/10.1007/ s40267-018-0531-1.

Katherine A. Lyseng-Williamson

dtp@adis.com

1 Springer, Mairangi Bay, Private Bag 65901, Auckland 0754, New Zealand

2 Department of Internal Medicine V, Comprehensive Pneumology Centre, University of Munich, Munich, Germany 